Rice DP (ed): Craniofacial Sutures. Development, Disease and Treatment.

Front Oral Biol. Basel, Karger, 2008, vol 12, pp 41-56

\title{
Mechanical Influences on Suture Development and Patency
}

\author{
Susan W. Herring \\ University of Washington, Seattle, Wash., USA
}

\begin{abstract}
In addition to their role in skull growth, sutures are sites of flexibility between the more rigid bones. Depending on the suture, predominant loading during life may be either tensile or compressive. Loads are transmitted across sutures via collagenous fibers and a fluid-rich extracellular matrix and can be quasi-static (growth of neighboring tissues) or intermittent (mastication). The mechanical properties of sutures, while always viscoelastic, are therefore quite different for tensile versus compressive loading. The morphology of individual sutures reflects the nature of local loading, evidently by a process of developmental adaptation. In vivo or ex vivo, sutural cells respond to tensile or cyclic loading by expressing markers of proliferation and differentiation, whereas compressive loading appears to favor osteogenesis. Braincase and facial sutures exhibit similar mechanical behavior and reactions despite their different natural environments.
\end{abstract}

Copyright (C) 2008 S. Karger AG, Basel

\section{Introduction}

Sutures are a part of the craniofacial skeleton and share its mechanical loads. At the same time sutures are obviously less stiff than the bones they join. This flexibility is the key to the particular mechanical roles played by sutures, which accommodate deformations of the skull that include distortions during birth (important for humans but probably less so for other species), distensions caused by internal pressures, cyclic loading from muscle activity, and traumatic impacts.

Like all components of the musculoskeletal system, sutures respond to mechanical loading. Indeed, the adaptability of sutures to their environment has been evident for decades, if not centuries. Although early workers analogized sutures to cartilaginous growth plates and assumed an independent growth 
capacity [1], most information since then has underscored the fact that sutural morphology and growth are easy to modify. This, of course, does not prove that the signal is a mechanical one, but it does point our attention to the local environment and phenomena that affect it. The study of mechanically induced transcription and expression in sutures is made complex by their compound nature, consisting of a variety of extracellular matrix zones, many different cell types, and a well-developed vasculature. Essentially all of these elements are known to respond to mechanical stimuli in isolation [2-7]. Thus, although it is no surprise to find that sutures also respond [8], it is difficult to sort out which cells are responsible. The same problem characterizes the very similar periodontal ligament, which is basically a suture between alveolar bone and the bone-like cementum that surrounds dental roots.

Although there is a large literature relating mechanics to suture biology, it is highly focused. Most studies have dealt with artificial loading of rodent vault or palatal sutures either in vitro or in vivo, with a smattering of rabbit and primate studies. Interest in these models centers around the identification of mechanically responsive transcription and expression. By comparison, understanding of how sutures actually behave under loading, i.e., their mechanical properties and what loads they receive in vivo, is less advanced. In this review an attempt will be made to synthesize these diverse areas. Readers are also referred to other recent reviews on the biology and mechanobiology of sutures [9-16]. For present purposes, sutures are considered to be the fibrocellular tissues that join membrane bones, but it is recognized that some of the most important aspects of suture biology concern the bone fronts rather than the sutures per se.

\section{Mechanical Properties of Sutures}

As explained in several current textbooks [17, 18], the engineering parameter most germane to suture biology is strain, technically defined as a change in length divided by original length, often expressed as a percentage. When forces place loads on solid objects, both stress and strain arise. Strain is thought to be the property sensed by cells, and in any case strain, in contrast to stress, is measurable. In elastic solids, stress divided by strain is a constant, the elastic modulus, roughly equivalent to stiffness.

In some nonmammalian vertebrate taxa, sutures are movable joints, contributing to range of movement rather than force transmission [19, 20]. In mammals, however, perhaps because of the requirements of forceful mastication, sutures are constructed for relatively efficient transmission of loads. They often feature interdigitating and/or overlapping bony fronts. Mature sutures are 
distinguished by well-developed fiber systems that not only unite the bone fronts, but also can resist deformation in tension, compression, or both [21, 22]. Sutures that show marked adaptation for force transmission can rival the strength of the bones they join [23, 24]. Nevertheless, sutures are zones of flexibility and energy absorption that undergo much greater deformations than the rigid bones of the skull regardless of rate or direction of loading [25-27].

The energy-absorbing qualities of sutures are related to their viscoelasticity, itself a result of their extracellular matrix of collagen fibers, proteoglycans, and water [28]. Thus their mechanical properties are nonlinear and influenced by loading rate and duration as fluid is forced out of the sutural space and collagen fibers are rearranged [29]. Probably because the fibers are usually organized to resist either predominantly compression or tension, mechanical properties can be quite different depending on the direction of loading [27]. As might be anticipated from the variety of bony morphologies and fiber arrangements, different sutures vary in their mechanical properties, with more interdigitated sutures typically showing higher elastic moduli [30].

The best studied aspect of sutural mechanical properties is their change with age. Force-bearing sutural ligaments that unite the bones are poorly, if at all, developed in fetal and early postnatal skulls [31]. Bony interdigitation is also a late-developing feature [32]. These changes imply that infant sutures should be less stiff and also less capable of energy absorption than older sutures, a finding supported by several studies [33-35]. Despite the fact that site-specific morphologies are not yet distinct, mechanical properties vary among different infant sutures. In week-old rats the posterior interfrontal suture was weaker and less stiff than the coronal or sagittal sutures [36]; interestingly, the posterior interfrontal suture is the only suture that fuses in this species [13].

\section{Strain Regimes in Relation to Mechanical Properties}

In life, the skull and its sutures are subjected to three types of strain regimes radically different in pattern and magnitude. The first type is impact loading from sudden forces produced accidentally from falls or foreign objects or produced intentionally by fighting. The latter are usually thought of in association with head-butting conflicts in horned ungulates, but also include human fighting styles such as boxing. Typically the magnitude of impact loads is high, as is the rate of loading. It seems unlikely that sutures could be adapted for unpredictable impact loading other than having a reasonable safety factor in mechanical properties. The most significant mechanical properties for resisting impacts are energy absorption capacity and ultimate strength. 




Fig. 1. Typical sutural strains measured during cyclic mastication in miniature pigs $[21,38,53,55]$. Arrows pointing away from the suture (premaxillary-maxillary, anterior interfrontal, interparietal, horizontal part of zygomatic) indicate tensile strain. Arrows pointing toward the suture (internasal, nasofrontal, posterior interfrontal and vertical part of zygomatic) indicate compressive strain. The coronal suture is individually variable and may be tensile, compressive or both [21]. Modified from Herring and Ochareon [51].

The second strain regime encountered by the skull and sutures is cyclic loading from function or from the pulsations of blood vessels [37]. Feeding (including ingestion, mastication and swallowing) is probably the major source of large-magnitude cyclic loading, but the skull also receives transmitted stresses from postcranial bones, for example during locomotion. Feeding loads result from muscle contraction, either directly (temporalis muscle pulling on parietal bone) or indirectly (reaction forces at the teeth or jaw joints). Cyclic functional loading produces fairly high strain rates. For example, rats typically chew at $5 \mathrm{~Hz}$, and the jaw closing muscles are active for no more than $50 \%$ of the cycle; thus, maximum loading would be achieved in $100 \mathrm{~ms}$ or less. Cyclic functional loading also features variable, but often high magnitudes of strain. As illustrated in figure 1, mastication in pigs can strain sutures up to $2,000 \mu \varepsilon$, 
either in compression (nasofrontal) or tension (zygomatic, premaxillary-maxillary) $[22,38]$. Stiffness, viscoelasticity and fatigue resistance would all affect the ability of a suture to deal with cyclic loads.

The third strain regime is quasi-static strain arising from the presence of adjacent tissues. Because the skull is generally conceived as an exoskeleton, these are usually interpreted as tensile strains caused by pressure from, or especially growth of, internal organs. For example, intracranial pressure from increasing brain volume has been calculated to produce quasi-static tensile strains on the order of $300 \mu \varepsilon$, which could either act directly on the suture [34] or indirectly through mechanotransduction by the dura mater [39]. An analog for facial sutures might be the cranial base cartilages and nasal septum, the growth of which could cause tension in the outer lying sutures. In the case of facial sutures any effect of strain must be direct, as there is no equivalent for the dura mater. Quasi-static strains can also come from external structures. For example, indentation of the braincase could be caused by stresses from enlarging musculature external to a suture. The weight of the head resisted by the vertebral column also constitutes a quasi-static load. Quasi-static strains are presumed to be low in magnitude and, of course, slow. Viscoelastic properties would be of special importance for sutural performance under such a strain regime.

\section{Sutures in situ: Normal Strain Environments}

Sutures do not exist until the osteogenic fronts of adjoining bones approximate each other, a comparatively late ontogenetic event. Mechanical loading, strictly speaking, is not possible until the structure exists. Nevertheless, the dramatic regional enlargements that characterize fetal development mean that quasi-static strains must be present in the future suture area. Such strains, which may cause ossification centers to separate in space, may have a role in suture positioning [40].

Once a suture has formed, loading is possible. Impact loading is not an element of normal development, and cyclic loading does not begin until muscles become active relatively late in mammalian ontogeny. However, quasi-static strains resulting from differential growth are probably very significant for sutures during fetal and infant life. Experimental alterations of intracranial pressure clearly do change suture morphology. Hydrocephaly modifies fiber orientation in the rat coronal suture from a compression-resisting to a tension-resisting architecture, whereas microcephaly thickens the bones without affecting the compression-resisting fibrous architecture [41]. Growth also seems to be affected, with tensile strain elongating bones at suture margins and 
compressive strain leading instead to thicker bones. Osteogenesis at the bone front tends to be greater at the attachment of fibers, i.e., tension sites [42]. Skulls from infants with hydrocephalus are thin but enlarged to house the increased intracranial contents [15]. In contrast, reduction of intracranial pressure by microcephaly produces small thick skulls with frequent synostosis. Mooney et al. [43] have summarized animal studies documenting suture stenosis in relation to microcephaly and shunting of hydrocephaly, which presumably reduce intracranial pressure levels and thus reduce tension (or increase compression) in sutures.

Cyclic strains from muscle contraction originate before birth as fetal jaw movements become coordinated [reviewed by 44] but paralysis apparently has no effect on developing sutures [45]. Postnatal muscle function acting on more mature sutures, however, does have an influence, as argued many years ago by Moss [46]. Suture strain resulting from muscle contraction can be tensile, compressive, or both, depending on the particular suture and the particular muscle, and magnitudes are typically an order of magnitude larger than strain on the adjacent bones [21, 22], reflecting the fact that sutures are much less stiff than bones. Increased jaw muscle force is associated with increased interdigitation and decreased tensile stiffness of the mouse sagittal suture [47], while a soft diet leads to simpler, narrower, and sometimes obliterated facial sutures in rats [48]. The toothless and therefore nonmasticating osteopetrotic (op/op) mouse shows similar changes in both facial and vault sutures, as well as poorly developed sutural ligaments $[49,50]$.

Although the absence of masticatory strain retards sutural growth, the growth rates of different sutures in normal animals are not correlated with the polarity of masticatory strain [51]. Sutural morphology, however, does show a specific relationship with the polarity of cyclic strain. Both in pigs and in fish, it has been reported that compressed sutures are more highly interdigitated $[51,52]$ than tensed sutures. In pigs it is clear that the prominent interdigitations are necessary for the fibers to be arranged in a compressionresistant orientation (fig. 2) [21,53]. Furthermore, an ontogenetic change in strain from compression to tension in the posterior interfrontal suture is associated with a simplification of the osteogenic fronts [54]. Another characteristic of sutures under cyclic compression is the presence of chondroid tissue or cartilage, which may permit rapid growth in a relatively anoxic environment [55].

There are no longitudinal or experimental studies evaluating the role of impact loading on sutures. Male wild sheep have more interdigitated sutures, particularly in the braincase, than females [56], but in addition to impact loading this could reflect quasi-static loading from heavier horns or higher-magnitude cyclic loading from larger muscles. 


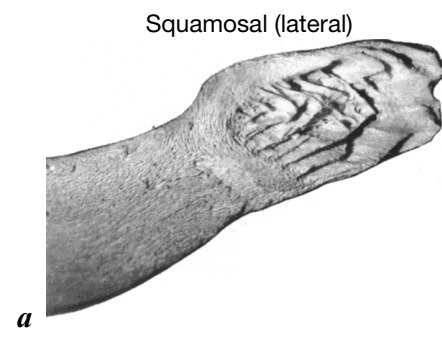

Zygomatic (medial)
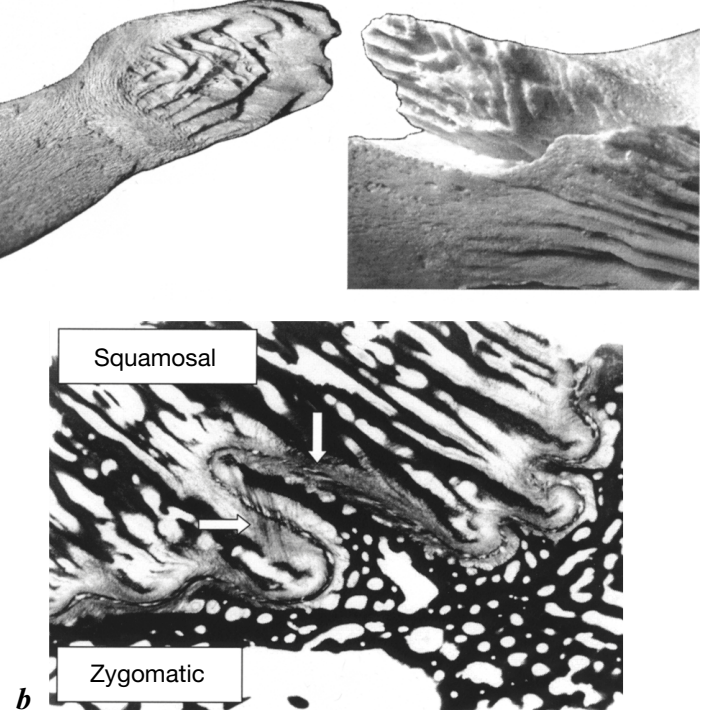

Fig. 2. Morphology of the pig zygomatic suture (vertical part), which undergoes cyclic compression during mastication. $\boldsymbol{a}$ The chevron-shaped interdigitating bony processes on the lateral surface of the left squamosal bone and the medial surface of the left zygomatic bone are shown. $\boldsymbol{b}$ The processes from the squamosal fitting into valleys of the zygomatic are shown. The sutural ligaments (white arrows) are arranged obliquely so that fibers will be stretched when the bones are forced together by the compressive load.

\section{Artificial Strain Environments in Intact Animals}

\section{Quasi-Static Tension: Elongated Osteogenic Fronts and Widened Sutures}

Although study of the natural mechanics of sutures is difficult, it is comparatively easy to impose an extrinsic force such as an orthodontic spring on sutures of the braincase and palate, and much of our knowledge comes from such experiments. Such loads fall into the quasi-static category. Most studies used tensile loads, because of the therapeutic potential of tension to grow bone (also used in distraction osteogenesis), but a few employed compression. The virtue of artificial strain regimes is the availability of sham controls, allowing some confidence that cell and molecular reactions to the imposed strains can be identified. In addition, in some cases similar strain regimes can be applied to organ cultures (see below), enabling a comparison of in vivo and in vitro responses. 
Quasi-static tensile loads have been applied in vivo to the sagittal suture of rats and mice [29,57-59], the internasal suture of rabbits [60], and the interpremaxillary and intermaxillary sutures of rats and macaques [61-65]. The latter imitates a common orthodontic treatment, rapid palatal expansion. Another clinical modality, a reverse head-gear appliance, has been used to apply tensile strain to multiple facial sutures in rats and macaques [66,67]. In terms of morphology and cell activity, this strain regime reliably produces increases in suture width, proliferation rate and vascularity, accompanied by increased matrix production and mineralization at the bone fronts $[60,62,67]$. Sutural ligament fibers and cells are frequently elongated in the direction of tension [57], and type III collagen, which is associated with adaptation to mechanical stress, is induced [58]. The rat midpalatal suture, which normally contains cartilage, is transformed to a ligamentous connection and expresses collagen I instead of collagen II, a response shown to be mediated by upregulation of $\beta_{1}$ integrin and the reorganization of the cytoskeleton [61]. As might be expected, expansion lowers sutural stiffness [29]. Stretching mouse sagittal sutures for 2 weeks caused the upregulation of not only type I collagen, but also alkaline phosphatase and osteopontin, probably by osteoblasts [59]. Thus the defect that results from the widened suture is rapidly ossified and the end result is elongated bone fronts [63]. Interestingly, the association between angiogenesis and osteogenesis may be more than a correlation, based on evidence that vascular pericytes are a major source of the expanded osteoprogenitor population $[64,65]$. Several of these studies compared different magnitudes of tensile loading, usually finding that increased loading resulted in a greater osteogenic response [57].

\section{Quasi-Static Compression: Thicker Bones, Narrower Sutures}

As mentioned above, there are comparatively few studies on sutures using quasi-static compressive loads in vivo. Head-gear appliances, which are assumed to compress multiple facial sutures, have been used in macaques [68], and miniplates have been placed across the coronal suture of fetal lambs, presumably causing compression as the bony fronts attempt to elongate [69]. Intrauterine constraint is usually considered as placing most sutures under compression [70,71]. Positional lambdoid suture plagiocephaly in humans may also be an example of quasi-static compression [72], as may artificial deformation of human or animal skulls, although in these cases compression at one suture may lead to tension at others $[73,74]$. The results of these disparate compression studies were essentially identical. The osteogenic fronts lengthened less, but the bones thickened. The sutures were narrowed, but in most studies did not fuse. In the monkey study some 'osteogenic' fronts actually became resorptive [68], and in human positional plagiocephaly, affected sutures showed heightened 
levels of TGF- $\beta_{3}$ [72], a growth factor implicated in preserving suture patency [75]. However, intrauterine constraint was associated with cartilage formation and occasional synostotic bridging of the human sagittal suture and the mouse squamosal and coronal sutures $[70,71]$.

\section{Cyclic Strain: Anabolic Regardless of Polarity}

Probably the most interesting experiments involving externally imposed loads are the recent series of papers by Mao and colleagues [76-79] in which cyclic forces were used. For these procedures animals were typically anesthetized each day for a short period of controlled loading. Although the loading was not physiological, its frequency and magnitude were roughly in the ranges for masticatory loading. Particularly informative was a comparison of two rabbit facial sutures, the nasofrontal and premaxillomaxillary, which were respectively shown to receive strong compression and mild tension when the incisor teeth were loaded [78]. In addition to a sham control, some animals received 'static' loading for $10 \mathrm{~min} /$ day - basically a single cycle, not equivalent to the sustained quasi-static loads discussed above. In another set of experiments, compressive cycles were imposed on rat incisors, although the strain regime on the sutures may have been tensile (gauges were evidently placed parallel to the suture rather than across it) [77, 79]. In all cases, the cyclically loaded sutures showed sutural widening with increased cells, followed in longer-term studies [78] by bone elongation. Bone thickness was not assessed, but additional observations on the rat sutures indicated that osteoclastic as well as osteoblastic activity was increased [79] and that the expression of MMP-2, a gelatinase possibly associated with mineralization [80], was upregulated, at least in the posterior frontal suture [77]. The remarkable finding of this work is the apparently identical reaction of sutures to cyclic compression and cyclic tension. Insofar as comparisons are possible, cyclic loading in either direction resembles quasi-static tension, producing a general growth response at the sutures. This result is quite different from the narrowing and stasis associated with quasi-static compression, but conforms with in vivo work showing that cyclic compression associated with mastication is perfectly consistent with vigorous suture growth [51].

\section{Sutures Strained in vitro: Gene Expression and Growth Factor Signaling}

Bones and sutures grown in culture are removed from the intrinsic strain regimes of the animal, resulting in different morphology. For example, in the 
absence of an expanding brain, osteogenic fronts that would approximate each other in vivo may form an overlapping suture instead [16]. Biologically, the systems are different as well, because in vitro preparations lack a blood supply (hence the very significant angiogenic reaction and pericyte invasion associated with in vivo quasi-static tension $[64,65]$ is eliminated) and can be examined with or without tissue layers such as the dura mater. In addition to the simpler (if not always realistic) biology, loads applied in vitro can be simpler as well, and thus better controlled. These preparations thus lend themselves to molecular analysis more easily than studies on intact animals.

As in vivo, quasi-static tension of mouse and rat sagittal sutures in vitro over a period of hours to days widened the sutures, stimulated proliferation of both osteoblastic and fibroblastic sutural cells, and led to elongation of the osteogenic fronts $[4,8,81]$. Striking changes in gene expression occurred almost immediately. After only $5 \mathrm{~min}$, stretched sutures released FGF-2 and demonstrated increased permeability and intracellular $\mathrm{Ca}^{2+}$ [82]. Other immediate events observed by various authors were the appearance of MMP-9, another gelatinase associated with mineralization [83], at stressed bone locations [14] and upregulation of TBX2, a probable inhibitor of osteogenesis, in the central part of the suture [84]. Within $90 \mathrm{~min}$, the expression of IGF-1 and its receptor was increased in both sutural fibroblasts and osteoblasts [81]. By $3 \mathrm{~h} \alpha$-adaptin $\mathrm{C}$, which is associated with endocytosis, was induced in central suture fibroblasts [8] and BMP-4 was expressed by osteoprogenitors [4]; by $6 \mathrm{~h}$, Cbfa1 was upregulated as well [4].

A model in which $30 \mathrm{~min}$ of quasi-static tension/day was applied to rat calvaria has been exploited to clarify the interaction of loading and the dura mater [85]. FGFs were noted to be produced by the dura mater, and in the absence of the dura, normally patent sutures fused. Tensile strain was found to delay or prevent the fusion of posterior interfrontal sutures, which were distinguished from unloaded (fusing) controls by the presence of FGFR1 at the osteogenic fronts and FGFR2 in the central area. The implication of these studies is that applied forces may work by influencing FGF signaling between the dura mater and the suture [85].

An in vitro cyclic compression regime (cited as unpublished observations by Ignelzi et al. [86]) was found to produce mouse sagittal suture fusion, not because the bones were pushed together but because of a general osteogenic response. This effect appeared to involve soluble factors manufactured by the loaded tissues, because cocultured unloaded sutures also showed osteogenesis and fusion. The osteogenic fronts in this loaded model were more cellular and showed more collagen than unloaded controls, but the faster-growing bone tissue was less mineralized [86]. 
Table 1. Summary of suture responses to strain regimes

\begin{tabular}{|c|c|c|c|c|}
\hline & \multicolumn{2}{|l|}{ Compression } & \multicolumn{2}{|l|}{ Tension } \\
\hline & quasi-static & cyclic & quasi-static & cyclic \\
\hline \multicolumn{5}{|l|}{ Examples } \\
\hline Intrinsic & Weight of head & Feeding & $\begin{array}{l}\text { Brain } \\
\text { enlargement }\end{array}$ & Feeding \\
\hline Extrinsic & Uterine constraint & In vitro loading & Palatal expansion & In vitro loading \\
\hline \multicolumn{5}{|l|}{ Suture } \\
\hline Width & Narrower & Wider & Wider & Wider \\
\hline Tissue & Cartilage common & Cartilage common & $\begin{array}{l}\text { More fibrous } \\
\text { More vascular }\end{array}$ & More fibrous \\
\hline Proliferation & Less & More & More & More \\
\hline Fibers & Less prominent & Oblique & Straight & Cruciate/straight \\
\hline \multicolumn{5}{|l|}{ Bone fronts } \\
\hline Growth & Less & More & More & More \\
\hline Morphology & Thicker & $\begin{array}{l}\text { Interdigitating } \\
\text { Chondroid common }\end{array}$ & Thinner & Flat \\
\hline
\end{tabular}

Although sutures also receive impact loads, their consequences are unknown. Because these responses are qualitatively similar in braincase and facial sutures, in vivo and in vitro, neither the dura mater nor a functioning vascular system appears to be required.

\section{Conclusions}

Sutures are viscoelastic structures that in vivo receive quasi-static, cyclic, and impact loads of various magnitudes, frequencies and directions. The loadbearing elements consist of the collagenous fibers of the sutural ligament supplemented by bound water. The compliance of sutures renders them far more deformable than the bones they join, and they are locations of energy absorption for the skull as a whole.

Sutures seem to react identically to tension whether intrinsic or extrinsic in origin, quasi-static or cyclic, in vitro or in vivo (table 1). Tension results in wider, more fibrous sutures abutted by thinner but elongated bones. The mechanical stimulus induces expression of markers of connective tissue and bone proliferation and differentiation through mechanisms that may initially involve calcium uptake and/or integrin binding. 
Delivered cyclically (either naturally or artificially), compressive strain behaves generally like tensile strain, maintaining sutural width and bone elongation. Because sutures in vivo are constructed to convert compression into tension via the sutural ligament, there may be little functional difference between cyclic tension and compression. It is also possible that a suture released periodically from compression experiences the release as a tensile strain, and vice versa.

In contrast, compressive strain delivered quasi-statically narrows sutures, retards bone growth in length but promotes bone thickening (table 1). Although synostosis sometimes accompanies compressive loading regimes, compression itself does not cause fusion. Rather, compression contributes to an osteogenic environment. Stimuli that enhance osteogenesis (or incapacitate osteogenic inhibitors) are well known to be associated with suture fusion [75, 87-95]. The narrowing of the suture space, development of cartilage, and immobility that sometimes accompany compression also facilitate fusion, but these effects are all indirect.

The most remarkable finding from the studies reviewed is the absence of a difference between the responses of braincase versus facial sutures to mechanical loads, despite the presence of the dura mater, a potent source of growth factors, in the former but not the latter. Similarly, in vitro and in vivo studies have yielded very similar findings even though a vascular supply accompanied by pericytes is absent in vitro. Thus the sutural tissues themselves must have sufficient responding elements.

\section{Acknowledgments}

I thank NIDCR for support of my work cited herein through award DE 08513 and Dr. Michael Cunningham for continuing interesting discussions on these topics.

\section{References}

1 Weinmann JP, Sicher H: Bone and Bones; Fundamentals of Bone Biology. St Louis, Mosby, 1947.

- Wang JH-C, Yang G, Li Z: Controlling cell responses to cyclic mechanical stretching. Ann Biomed Eng 2005;33:337-342.

- Wang JH-C, Yang G, Li Z, Shen W: Fibroblast responses to cyclic mechanical stretching depend on cell orientation to the stretching direction. J Biomech 2004;37:573-576.

4 Ikegame M, Ishibashi O, Yoshizawa T, Shimomura J, Komori T, Ozawa H, Kawashima H: Tensile stress induces bone morphogenetic protein 4 in preosteoblastic and fibroblastic cells, which later differentiate into osteoblasts leading to osteogenesis in the mouse calvariae in organ culture. $\mathrm{J}$ Bone Miner Res 2001;16:24-32.

-5 Chiquet M, Renedo AS, Huber F, Flück M: How do fibroblasts translate mechanical signals into changes in extracellular matrix production? Matrix Biol 2003;22:73-80. 
6 Von den Hoff JW: Effects of mechanical tension on matrix degradation by human periodontal ligament cells cultured in collagen gels. J Periodontal Res 2003;38:449-457.

7 Redlich M, Roos HA, Reichenberg E, Zaks B, Mussig D, Baumert U, Golan I, Palmon A: Expression of tropoelastin in human periodontal ligament fibroblasts after stimulation of orthodontic force. Arch Oral Biol 2004;49:119-124.

$>8$ Shimomura J, Ishibashi O, Ikegame M, Yoshizawa T, Ejiri S, Noda T, Kawashima H: Tensile stress induces $\alpha$-adaptin $\mathrm{C}$ production in mouse calvariae in an organ culture: possible involvement of endocytosis in mechanical stress-stimulated osteoblast differentiation. $J$ Cell Physiol 2003;195:488-496.

-9 Mao JJ, Wang P, Kopher RA: Biomechanics of craniofacial sutures: orthopedic implications. Angle Orthod 2003;73:128-135.

10 Mao JJ: Mechanobiology of craniofacial sutures. J Dent Res 2002;81:810-816.

11 Mao JJ, Nah HD: Growth and development: hereditary and mechanical modulations. Am J Orthod Dentofacial Orthop 2004;125:676-689.

$\checkmark 12$ Warren SM, Greenwald JA, Spector JA, Bouletreau P, Mehrara BJ, Longaker MT: New developments in cranial suture research. Plast Reconstr Surg 2001;107:523-540.

13 Opperman LA: Cranial sutures as intramembranous bone growth sites. Dev Dyn 2000;219: $472-485$.

14 Yu JC, Borke JL, Zhang G: Brief synopsis of cranial sutures: optimization by adaptation. Semin Pediatr Neurol 2004;11:249-255.

15 Huggare J, Rönning O: Growth of the cranial vault; in Dixon AD, Hoyte DAN, Rönning O (eds): Fundamentals of Craniofacial Growth. Boca Raton, CRC Press, 1997, pp 363-387.

16 Rice DPC, Rice R, Thesleff I: Molecular mechanisms in calvarial bone and suture development, and their relation to craniosynostosis. Eur J Orthod 2003;25:139-148.

17 Martin RB, Burr DB, Sharkey NA: Skeletal Tissue Mechanics. New York, Springer, 1998.

18 Carter DR, Beaupré GS: Skeletal Function and Form. Cambridge, Cambridge University Press, 2001.

19 Gussekloo SWS, Vosselman MG, Bout RG: Three-dimensional kinematics of skeletal elements in avian prokinetic and rhynchokinetic skulls determined by Roentgen stereophotogrammetry. J Exp Biol 2001;204:1735-1744.

20 Iordansky NN: Evolution of cranial kinesis in lower tetrapods. Neth J Zool 1990;40:32-54.

21 Herring SW, Teng S: Strain in the braincase and its sutures during function. Am J Phys Anthropol 2000;112:575-593.

22 Herring SW, Rafferty KL: Cranial and facial sutures: functional loading in relation to growth and morphology; in Davidovitch Z, Mah J (eds): Biological Mechanisms of Tooth Movement and Craniofacial Adaptation. Boston, Harvard Society for the Advancement of Orthodontics, 2000, pp 269-276.

23 Hubbard RP, Melvin JW, Barodawala IT: Flexure of cranial sutures. J Biomech 1971;4:491-496.

24 Jaslow CR: Mechanical properties of cranial sutures. J Biomech 1990;23:313-321.

25 Jaslow CR, Biewener AA: Strain patterns in the horncores, cranial bones and sutures of goats (Capra hircus) during impact loading. J Zool 1995;235:193-210.

26 Herring SW: Sutures and craniosynostosis: a comparative, functional, and evolutionary perspective; in Cohen MMJ, MacLean RE (eds): Craniosynostosis, ed 2. New York, Oxford University Press, 2000, pp 3-10.

27 Popowics TE, Herring SW: Load transmission in the nasofrontal suture of the pig, Sus scrofa. J Biomech 2007;40:837-844.

28 Woo SL-Y, Akeson WH: Response of tendons and ligaments to joint loading and movements; in Helminen HJ, Tammi M, Kiviranta I, Paukkonen K, Säämänen A-M, Jurvelin J (eds): Joint Loading. Bristol, Wright, 1987, pp 287-315.

29 Tanaka E, Miyawaki Y, del Pozo R, Tanne K: Changes in the biomechanical properties of the rat interparietal suture incident to continuous tensile force application. Arch Oral Biol 2000;45:1059-1064.

30 Radhakrishnan P, Mao JJ: Nanomechanical properties of facial sutures and sutural mineralization front. J Dent Res 2004;83:470-475.

31 Pritchard JJ, Scott JH, Girgis FG: The structure and development of cranial and facial sutures. J Anat 1956;90:73-87. 
32 Persson M: Structure and growth of facial sutures. Odont Revy 1973;24(suppl 26):1-146.

-33 Margulies SS, Thibault KL: Infant skull and suture properties: measurements and implications for mechanisms of pediatric brain injury. J Biomech Eng 2000;122:364-371.

34 Henderson JH, Chang LY, Song HM, Longaker MT, Carter DR: Age-dependent properties and quasi-static strain in the rat sagittal suture. J Biomech 2005;38:2294-2301.

35 Gefen A, Gefen N, Zhu Q, Raghupathi R, Margulies SS: Age-dependent changes in material properties of the brain and braincase of the rat. J Neurotrauma 2003;20:1163-1177.

-36 McLaughlin E, Zhang Y, Pashley D, Borke J, Yu J: The load-displacement characteristics of neonatal rat cranial sutures. Cleft Palate Craniofac J 2000;37:590-595.

37 Oudhof HAJ, van Doorenmaalen WJ: Skull morphogenesis and growth: hemodynamic influence. Acta Anat 1983;117:181-186.

38 Rafferty KL, Herring SW, Marshall CD: The biomechanics of the rostrum and the role of facial sutures. J Morphol 2003;257:33-44.

39 Henderson JH, Longaker MT, Carter DR: Sutural bone deposition rate and strain magnitude during cranial development. Bone 2004;34:271-280.

40 Persson M, Roy W: Suture development and bony fusion in the fetal rabbit palate. Arch Oral Biol 1979;24:283-291.

41 Prahl-Andersen B: Sutural Growth; doctoral dissertation, University of Nijmegen, 1968.

42 Koskinen L: Adaptive sutures. Proc Finnish Dent Soc 1977;73(suppl 10):1-67.

43 Mooney MP, Siegel MI, Opperman LA: Animal models of craniosynostosis: experimental, congenital, and transgenic models; in Mooney MP, Siegel MI (eds): Understanding Craniofacial Anomalies: the Etiopathogenesis of Craniosynostoses and Facial Clefting. New York, Wiley-Liss, 2002, pp 209-249.

44 Herring SW: The ontogeny of mammalian mastication. Am Zool 1985;25:339-349.

45 Persson M: The role of movements in the development of sutural and diarthrodial joints tested by long-term paralysis of chick embryos. J Anat 1983;137:591-599.

-46 Moss ML: Extrinsic determination of sutural area morphology in the rat calvaria. Acta Anat 1961;44:263-272.

47 Byron CD, Borke J, Yu J, Pashley D, Wingard CJ, Hamrick M: Effects of increased muscle mass on mouse sagittal suture morphology and mechanics. Anat Rec 2004;279A:676-684.

48 Engström C, Kiliaridis S, Thilander B: The relationship between masticatory function and craniofacial morphology. II. A histological study in the growing rat fed a soft diet. Eur J Orthod 1986;8:271-279.

49 Kaku M, Kawata T, Kawasoko S, Fujita T, Tokimasa C, Tanne K: Remodeling of the sagittal suture in osteopetrotic (op/op) mice associated with cranial flat bone growth. J Craniofac Genet Dev Biol 1999;19:109-112.

50 Kawata T, Tokimasa C, Fujita T, Kaku M, Kawasoko S, Sugiyama H, Ozawa S, Tanne K: Morphological change of the nasopremaxillary suture in growing 'toothless' osteopetrotic (op/op) mice. J Craniofac Genet Dev Biol 1999;19:48-55.

51 Herring SW, Ochareon P: Bone - special problems of the craniofacial region. Orthod Craniofac Res 2005;8:174-182.

52 Markey M, Main R, Marshall C: In vivo cranial suture function and suture morphology in extant fish: implications for inferring skull function in fossil taxa. J Vert Paleontol 2005;25(suppl): 88A-89A.

53 Herring SW, Mucci RJ: In vivo strain in cranial sutures: the zygomatic arch. J Morphol 1991;207:225-239.

54 Sun Z, Lee E, Herring SW: Cranial sutures and bones: growth and fusion in relation to masticatory strain. Anat Rec 2004;276A:150-161.

55 Rafferty KL, Herring SW: Craniofacial sutures: morphology, growth and in vivo masticatory strains. J Morphol 1999;242:167-179.

56 Jaslow CR: Sexual dimorphism of cranial suture complexity in wild sheep (Ovis aries). Zool J Linn Soc 1989;95:273-284.

57 Miyawaki S, Forbes DP: The morphologic and biochemical effects of tensile force application to the interparietal suture of the Sprague-Dawley rat. Am J Orthod 1987;92:123-133.

58 Tanaka E, Miyawaki Y, Tanaka M, Watanabe M, Lee K, del Pozo R, Tanne K: Effects of tensile forces on the expression of type III collagen in rat interparietal suture. Arch Oral Biol 2000;45:1049-1057. 
59 Morinobu M, Ishijima M, Rittling SR, Tsuji K, Yamamoto H, Nifuji A, Denhardt DT, Noda M: Osteopontin expression in osteoblasts and osteocytes during bone formation under mechanical stress in the calvarial suture in vivo. J Bone Miner Res 2003;18:1706-1715.

60 Parr JA, Garetto LP, Wohlford ME, Arbuckle GR, Roberts WE: Sutural expansion using rigidly integrated endosseous implants: an experimental study in rabbits. Angle Orthod 1997;67:283-290.

61 Takahashi I, Onodera K, Sasano Y, Mizoguchi I, Bae JW, Mitani H, Kagayama M: Effect of stretching on gene expression of beta1 integrin and focal adhesion kinase and on chondrogenesis through cell-extracellular matrix interactions. Eur J Cell Biol 2003;82:182-192.

62 Southard KA, Forbes DP: The effects of force magnitude on a sutural model: a quantitative approach. Am J Orthod Dentofacial Orthop 1988;93:460-466.

63 Cleall JF, Bayne DI, Posen JM, Subtelny JD: Expansion of the midpalatal suture in the monkey. Angle Orthod 1965;35:23-35.

64 Chang H-N, Garetto LP, Katona TR, Potter RH, Roberts WE: Angiogenic induction and cell migration in an orthopaedically expanded maxillary suture in the rat. Arch Oral Biol 1996;41: 985-994.

65 Chang H-N, Garetto LP, Potter RH, Katona TR, Lee C-H, Roberts WE: Angiogenesis and osteogenesis in an orthopedically expanded suture. Am J Orthod Dentofacial Orthop 1997;111:382-390.

66 Sasaki A, Sugiyama Y, Tanaka E, Sugiyama M: Effects of sutural distraction osteogenesis applied to rat maxillary complex on craniofacial growth. J Oral Maxillofac Surg 2002;60:667-675.

67 Jackson GW, Kokich VG, Shapiro PA: Experimental and postexperimental response to anteriorly directed extraoral force in young Macaca nemestrina. Am J Orthod 1979;75:318-333.

68 Elder JR, Tuenge RH: Cephalometric and histologic changes produced by extraoral high-pull traction to the maxilla in Macaca mulatta. Am J Orthod 1974;66:599-617.

69 Bradley JP, Shahinian H, Levine JP, Rowe NM, Longaker MT: Growth restriction of cranial sutures in the fetal lamb causes deformational changes, not craniosynostosis. Plast Reconstr Surg 2000;105:2416-2423.

70 Koskinen-Moffett L, Moffett BC: Sutures and intrauterine deformation; in Persing JA, Edgerton MT, Jane JA (eds): Scientific Foundations and Surgical Treatment of Craniosynostosis. Baltimore, Williams \& Wilkins, 1989, pp 96-106.

71 Koskinen-Moffett LK, Moffett BC Jr, Graham JM Jr: Cranial synostosis and intra-uterine compression: a developmental study of human sutures. Prog Clin Biol Res 1982;101:365-378.

72 Lin KY, Nolen AA, Gampper TJ, Jane JA, Opperman LA, Ogle RC: Elevated levels of transforming growth factors beta 2 and beta 3 in lambdoid sutures from children with persistent plagiocephaly. Cleft Palate Craniofac J 1997;34:331-337.

73 Anton SC, Jaslow CR, Swartz SM: Sutural complexity in artificially deformed human (Homo sapiens) crania. J Morphol 1992;214:321-332.

74 Burrows AM, Caruso KA, Mooney MP, Smith TD, Losken HW, Siegel MI: Sutural bone frequency in synostotic rabbit crania. Am J Phys Anthropol 1997;102:555-563.

75 Opperman LA, Chhabra A, Cho RW, Ogle RC: Cranial suture obliteration is induced by removal of transforming growth factor (TGF)- $\beta 3$ activity and prevented by removal of TGF- $\beta 2$ activity from fetal rat calvaria in vitro. J Craniofac Genet Dev Biol 1999;19:164-173.

76 Al-Mubarak R, Da Silveira A, Mao JJ: Expression and mechanical modulation of matrix metalloproteinase-1 and -2 genes in facial and cranial sutures. Cell Tissue Res 2005;321:465-471.

77 Collins JM, Ramamoorthy K, Da Silveira A, Patston P, Mao JJ: Expression of matrix metalloproteinase genes in the rat intramembranous bone during postnatal growth and upon mechanical stresses. J Biomech 2005;38:485-492.

78 Kopher RA, Mao JJ: Suture growth modulated by the oscillatory component of micromechanical strain. J Bone Miner Res 2003;18:521-528.

79 Vij K, Mao JJ: Geometry and cell density of rat craniofacial sutures during early postnatal development and upon in vivo cyclic loading. Bone 2006;38:722-730.

80 Satoyoshi M, Kawata A, Koizumi T, Inoue K, Itohara S, Teranaka T, Mikuni-Takagaki Y: Matrix metalloproteinase-2 in dentin matrix mineralization. J Endod 2001;27:462-466.

81 Hirukawa K, Miyazawa K, Maeda H, Kameyama Y, Goto S, Togari A: Effect of tensile force on the expression of IGF-1 and IGF-1 receptor in the organ-cultured rat cranial suture. Arch Oral Biol 2005;50:367-372. 
82 Yu JC, Lucas JH, Fryberg K, Borke JL: Extrinsic tension results in FGF-2 release, membrane permeability change, and intracellular $\mathrm{Ca}^{2+}$ increase in immature cranial sutures. J Craniofac Surg 2001;12:391-398.

83 Miao D, Bai X, Panda DK, Karaplis AC, Goltzman D, McKee MD: Cartilage abnormalities are associated with abnormal Phex expression and with altered matrix protein and MMP-9 localization in Hyp mice. Bone 2004;34:638-647.

84 Borke JL, Yu JC, Isales CM, Wagle N, Do NN, Chen JR, Bollag RJ: Tension-induced reduction in connexin 43 expression in cranial sutures is linked to transcriptional regulation by TBX2. Ann Plast Surg 2003;51:499-504.

85 Ogle RC, Tholpady SS, McGlynn KA, Ogle RA: Regulation of cranial suture morphogenesis. Cells Tissues Organs 2004;176:54-66.

86 Tarnowski CP, Ignelzi MA Jr, Wang W, Taboas JM, Goldstein SA, Morris MD: Earliest mineral and matrix changes in force-induced musculoskeletal disease as revealed by Raman microspectroscopic imaging. J Bone Miner Res 2004;19:64-71.

87 Yu P, Gosain AK, Khanna A: The role of transforming growth factor-beta in the modulation of mouse cranial suture fusion. Plast Reconstr Surg 2001;108:916-924.

88 Yoshida T, Phylactou LA, Uney JB, Ishikawa I, Eto K, Iseki S: Twist is required for establishment of the mouse coronal suture. J Anat 2005;206:437-444.

89 Warren SM, Brunet LJ, Harland RM, Economides AN, Longaker MT: The BMP antagonist noggin regulates cranial suture fusion. Nature 2003;422:625-629.

$\$ 90$ Dodig M, Tadic T, Kronenberg MS, Cacic S, Liu Y-H, Maxson R, Rowe DW, Lichtler AC: Ectopic $M s x 2$ overexpression inhibits and $M s x 2$ antisense stimulates calvarial osteoblast differentiation. Dev Biol 1999;209:298-307.

91 Greenwald JA, Mehrara BJ, Spector JA, Warren SM, Fagenholz PJ, Smith LP, Bouletreau PJ, Crisera FE, Ueno $\mathrm{H}$, Longaker MT: In vivo modulation of FGF biological activity alters cranial suture fate. Am J Pathol 2001;158:441-452.

$\$ 92$ Liu Y-H, Tang Z, Kundu RK, Wu L, Luo W, Zhu D, Sangiorgi F, Snead ML, Maxson REJ: Msx2 gene dosage influences the number of proliferative osteogenic cells in growth centers of the developing murine skull: a possible mechanism for MSX2-mediated craniosynostosis in humans. Dev Biol 1999;205:260-274.

$\$ 93$ Opperman LA, Chhabra A, Nolen AA, Bao Y, Ogle RC: Dura mater maintains rat cranial sutures in vitro by regulating suture cell proliferation and collagen production. J Craniofac Genet Dev Biol 1998;18:150-158.

$\$ 94$ Yu H-MI, Jerchow B, Sheu T-J, Liu B, Costantini F, Puzas JE, Birchmeier W, Hsu W: The role of Axin2 in calvarial morphogenesis and craniosynostosis. Development 2005;132:1995-2005.

$\$ 95$ Nacamuli RP, Fong KD, Lenton KA, Song HM, Fang TD, Salim A, Longaker MT: Expression and possible mechanisms of regulation of BMP3 in rat cranial sutures. Plast Reconstr Surg 2005;116:1353-1362.

Susan W. Herring

Department of Orthodontics, University of Washington

Box 357446

Seattle, WA $98195-7446$ (USA)

Tel. +1 206543 3203, Fax +1 206685 8163, E-Mail herring@u.washington.edu 